\title{
Shared control of maltose and trehalose utilization in Candida utilis
}

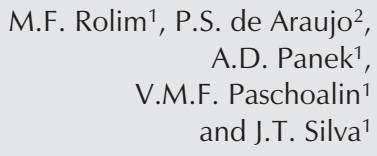

\author{
'Departamento de Bioquímica, Instituto de Química, \\ Universidade Federal do Rio de Janeiro, Rio de Janeiro, RJ, Brasil \\ ${ }^{2}$ Departamento de Bioquímica, Instituto de Química, \\ Universidade de São Paulo, São Paulo, SP, Brasil
}

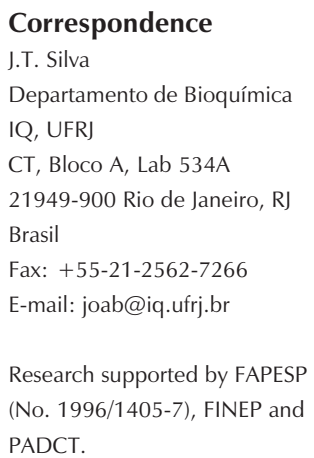

Received September 11, 2002 Accepted February 26, 2003

\begin{abstract}
Trehalose biosynthesis and its hydrolysis have been extensively studied in yeast, but few reports have addressed the catabolism of exogenously supplied trehalose. Here we report the catabolism of exogenous trehalose by Candida utilis. In contrast to the biphasic growth in glucose, the growth of $C$. utilis in a mineral medium with trehalose as the sole carbon and energy source is aerobic and exhibits the Kluyver effect. Trehalose is transported into the cell by an inducible trehalose transporter $\left(K_{\mathrm{M}}\right.$ of $8 \mathrm{mM}$ and $V_{\mathrm{MAX}}$ of $1.8 \mu \mathrm{mol}$ trehalose $\mathrm{min}^{-1} \mathrm{mg}$ cell (dry weight) ${ }^{-1}$. The activity of the trehalose transporter is high in cells growing in media containing trehalose or maltose and very low or absent during the growth in glucose or glycerol. Similarly, total trehalase activity was increased from about $1.0 \mathrm{mU} / \mathrm{mg}$ protein in cells growing in glucose to 39.0 and $56.2 \mathrm{mU} / \mathrm{mg}$ protein in cells growing in maltose and trehalose, respectively. Acidic and neutral trehalase activities increased during the growth in trehalose, with neutral trehalase contributing to about $70 \%$ of the total activity. In addition to the increased activities of the trehalose transporter and trehalases, growth in trehalose promoted the increase in the activity of $\alpha$-glucosidase and the maltose transporter. These results clearly indicate that maltose and trehalose promote the increase of the enzymatic activities necessary to their catabolism but are also able to stimulate each other's catabolism, as reported to occur in Escherichia coli. We show here for the first time that trehalose induces the catabolism of maltose in yeast.
\end{abstract}

Key words

- Trehalose

- Trehalase

- Sugar transporter

- Candida utilis

- Yeast

\section{Introduction}

In yeast, the first step in the utilization of a disaccharide is usually its movement across the plasma membrane from the external medium into the cytosol by means of a stereospecific carrier. The second step is the intracellular hydrolysis of the sugar into its component monomers before their subsequent catabolism through the glycolytic pathway. However, some yeast species have gly- cosidases acting outside the plasma membrane, so that the monosaccharides formed by hydrolysis, rather than the disaccharide itself, are carried into the cell (1).

Trehalose [O- $\alpha$-D-glucopyranosyl- $(1,1)$ $\alpha$-D-glucopyranose] is a nonreducing disaccharide, which has been isolated from algae, bacteria, fungi, insects, invertebrates, and yeasts, as well as from some lower vascular plants and a few flowering plants (2). Several yeast species can use this sugar as the 
sole carbon and energy source, although in different ways. Trehalose can be hydrolyzed to glucose by an extracellular trehalase (EC 3.2.1.28) as observed in Rhodotorula rubra (3), or it can be transported into the cell and hydrolyzed by an intracellular trehalase, as in Saccharomyces cerevisiae and Trichosporon cutaneum (4,5). Candida utilis has been reported to be able to assimilate trehalose (6), but the mechanism involved has not been determined.

In S. cerevisiae, the enzyme for trehalose hydrolysis exists in two soluble intracellular forms (7) with distinct functions: a regulatory cytosolic neutral trehalase responsible for the mobilization of stored trehalose (8) and a nonregulatory vacuolar acid trehalase involved in the catabolism of exogenous trehalose (9). Similarly, more than $97 \%$ of the trehalase activity present in whole-cell extracts of C. utilis was recovered from highspeed supernatants of broken cells without significant association with particulate cell wall or membrane fractions (10). This soluble intracellular trehalase activity was the sum of two different enzymes: a neutral, cytoplasmic, regulated trehalase, which is under the control of the cAMP-dependent protein kinase $(11,12)$ and a nonregulated, acidic trehalase located in the vacuole (10). Since these results were obtained for a strain unable to grow in trehalose (10), they are not informative about the metabolic route followed by external trehalose to enter the glycolytic cycle in C. utilis.

In the present study we investigated the initial steps of trehalose catabolism in $C$. utilis growing in a mineral medium with trehalose as the sole carbon and energy source. We found that this yeast takes up trehalose by a disaccharide transporter that is present when cells are growing in trehalose or maltose, but not when they are growing in glucose or glycerol. In a concerted way with the activity of the trehalose transporter, the activities of acidic and neutral trehalase as well as $\alpha$-glucosidase were also increased during growth in maltose or trehalose media. For the first time we showed that in yeast cells trehalose and maltose cross-regulate each other's catabolism, as already reported to occur in Escherichia coli (13).

\section{Material and Methods}

\section{Microorganisms and growth conditions}

All experiments were conducted using the $C$. utilis strain Tha. Cells were grown in YNB medium $(0.67 \%$ yeast nitrogen base, Difco Laboratories, Sparks, MD, USA) containing $1 \%$ trehalose, $1 \%$ maltose, $1 \%$ sucrose or $3 \%$ glycerol as the carbon source. Cultures were grown in $100 \mathrm{ml}$ of medium in 500-ml Erlenmeyer flasks at $28^{\circ} \mathrm{C}$, in an orbital shaker operated at $160 \mathrm{rpm}$ to ensure aeration. Culture growth was monitored by turbidity measurements at $570 \mathrm{~nm}$.

\section{Cell-free extracts}

Cells (50 mg dry weight) were harvested by centrifugation at 4,000 $\mathrm{g}$ for $5 \mathrm{~min}$ and washed twice with cold distilled water. Washed cells were suspended in $0.5 \mathrm{ml}$ of chilled 0.1 M MOPS buffer, $\mathrm{pH}$ 7.0, and transferred to a $15-\mathrm{ml}$ Corex tube containing $2.0 \mathrm{~g}$ of glass beads $(0.45 \mathrm{~mm}$ in diameter). Cells were disrupted by shaking ( 3 cycles of 1 min at 1-min intervals in an ice bath) in a vortex mixer at maximum speed. Cell-free extracts were obtained by centrifugation of the broken cell suspensions at $12,000 \mathrm{~g}$ for 5 min. Protein was measured by the minibiuret method of Layne (14) using bovine serum albumin as standard.

\section{Synthesis of $\left[{ }^{14} \mathrm{C}\right]$-labeled trehalose}

${ }^{14}[\mathrm{C}]$-trehalose was produced from uniformly labeled ${ }^{14}[\mathrm{C}]$-D-glucose using an $S$. cerevisiae strain lacking the $P G I 1$ gene coding for phosphoglucoisomerase (15). 


\section{Trehalase activity}

Total, neutral and acidic trehalase activities were assayed by modification of a previous procedure (10). Total trehalase activity was assessed in an assay mixture containing $20 \mu$ mol sodium phosphate buffer, $\mathrm{pH}$ 5.6, $20 \mu \mathrm{mol}$ trehalose and $50-100 \mu \mathrm{g}$ protein in a final volume of $0.2 \mathrm{ml}$. Acidic trehalase activity was determined with this assay with the addition of $0.8 \mu \mathrm{mol} \mathrm{ZnCl}_{2}$ to inhibit neutral trehalase. Neutral trehalase activity was measured in an assay mixture containing $20 \mu \mathrm{mol}$ sodium acetate buffer, $\mathrm{pH} 5.6$ (to inhibit acid trehalase), $20 \mu \mathrm{mol}$ trehalose and 50-100 $\mu \mathrm{g}$ protein in a final volume of $0.2 \mathrm{ml}$. After incubation at $30^{\circ} \mathrm{C}$ for $15 \mathrm{~min}$, the reactions were stopped by heating at $100^{\circ} \mathrm{C}$ for $3 \mathrm{~min}$ in a water bath. The glucose produced was measured by a modification of the glucose oxidase/peroxidase method (16). A unit of trehalase is defined as the amount of enzyme able to release $1 \mu \mathrm{mol}$ glucose per minute under standard conditions.

\section{Extracellular glycosidase activities}

Extracellular activities of trehalase, $\alpha$ glucosidase and invertase were measured in assay mixtures containing $50 \mu \mathrm{g}$ (dry weight) of intact washed cells, $5 \mu \mathrm{mol}$ sodium acetate buffer, $\mathrm{pH} 4.8$, and $20 \mu \mathrm{mol}$ trehalose, maltose or sucrose in a final volume of 200 $\mu 1$. After $30 \mathrm{~min}$ at $30^{\circ} \mathrm{C}$ the reactions were stopped by centrifugation at $12,000 \mathrm{~g}$ for $15 \mathrm{~s}$. Glucose content in the supernatant was determined as described (16). A unit of glycosidase activity is defined as the amount of cells able to release $1 \mu \mathrm{mol}$ glucose per minute under standard conditions.

Trehalose transporter activity was assayed by modification of a previously described method (17). Cells (10 mg dry weight) were harvested by centrifugation at $4,000 \mathrm{~g}$ for 5 min, washed twice with cold $0.08 \mathrm{M}$ Trissuccinate buffer, $\mathrm{pH}$ 5.0, and resuspended in the same buffer at a concentration of $10 \mathrm{mg}$ (dry weight) $/ \mathrm{ml}$. Trehalose transporter activity was determined in $0.2 \mathrm{ml}$ of $40 \mathrm{mM}$ Trissuccinate buffer, $\mathrm{pH}$ 5.0, containing $200 \mu \mathrm{g}$ (dry weight) of cells and $1 \mu \mathrm{mol}$ trehalose carrier with $1.4 \times 10^{5} \mathrm{cpm}\left[{ }^{14} \mathrm{C}\right]$-trehalose. After time intervals of $30 \mathrm{~s}$ and $1 \mathrm{~min}$ at $25^{\circ} \mathrm{C}, 100-\mu 1$ aliquots were removed and cells were rapidly filtered through nitrocellulose filters and rinsed with $10 \mathrm{ml}$ of icecold distilled water. The radioactivity retained on the filters was determined with a Beckman liquid scintillation counter (Beckman, Irvine, CA, USA). Initial transport rates were obtained from linear regression of duplicate experiments. Controls were performed using either previously boiled cells or cells maintained at $4^{\circ} \mathrm{C}$.

\section{Maltose transporter activity}

Maltose transporter activity was measured using the $p$-nitrophenyl- $\alpha$-D-glucoside (PNPG) method (18). Cells (10 mg dry weight) were harvested by centrifugation at 4,000 g for $5 \mathrm{~min}$, washed twice with cold

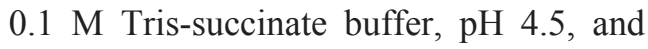
resuspended in the same buffer at a concentration of $10 \mathrm{mg}$ (dry weight) $/ \mathrm{ml}$. Maltose transport was determined in $1 \mathrm{ml}$ of $0.1 \mathrm{M}$ Tris-succinate buffer, $\mathrm{pH} 4.5$, containing $1 \mathrm{mg}$ (dry weight) of cells and $2 \mathrm{mM}$ PNPG. The reaction was performed for 10-20 min at $30^{\circ} \mathrm{C}$ and stopped by the addition of $0.5 \mathrm{M}$ $\mathrm{Na}_{2} \mathrm{CO}_{3} \cdot p$-Nitrophenol (PNP) formed was measured by absorbance at $420 \mathrm{~nm}$.

Intracellular $\alpha$-glucosidase activity was measured as described previously (19). Cells (10 mg dry weight) were harvested by centrifugation at $4,000 \mathrm{~g}$ for $5 \mathrm{~min}$, washed twice with cold $0.1 \mathrm{M}$ phosphate buffer, $\mathrm{pH}$ 6.5 , and resuspended in the same buffer to a final volume of $0.9 \mathrm{ml}$. Permeabilized yeast cells were obtained by the addition of $0.1 \mathrm{ml}$ of toluene/ethanol/Triton X-100 (1:4:0.02, $\mathrm{v} / \mathrm{v} / \mathrm{v}$ ) and shaken in a vortex mixer at maximum speed for $3 \mathrm{~min}$. Permeabilized cells were washed twice with cold phosphate 
fer and resuspended in the same buffer to a final concentration of $10 \mathrm{mg}$ (dry weight)/ml. $\alpha$-Glucosidase activity was assayed in $1 \mathrm{ml}$ of $0.1 \mathrm{M}$ phosphate buffer, $\mathrm{pH}$ 6.5, containing $1 \mathrm{mg}$ (dry weight) of cells, and $2 \mathrm{mM}$ PNPG at $30^{\circ} \mathrm{C}$ for 5-10 min. The reaction was stopped by the addition of $0.5 \mathrm{M} \mathrm{Na}_{2} \mathrm{CO}_{3}$ and the PNP formed was determined by absorbance at 420 $\mathrm{nm}$. A unit of $\alpha$-glucosidase is defined as the amount of cells able to release $1 \mu \mathrm{mol}$ PNP per minute under standard conditions.

\section{Results and Discussion}

\section{Trehalose promotes Candida utilis growth}

The strain of $C$. utilis used in the present study was able to grow in minimum mineral medium (YNB) containing 1\% glucose, $1 \%$ maltose, $1 \%$ trehalose, $1 \%$ sucrose or $3 \%$ glycerol as the sole carbon and energy source. Cultures in YNB-1\% glucose or YNB-1\% trehalose reached the same cell density after $43 \mathrm{~h}$ of incubation, although they exhibited very characteristic curves (Figure 1). Growth in glucose was biphasic with a generation time of $2 \mathrm{~h}$ during the first exponential growth phase and displayed a diauxic (adaptive) phase of $3 \mathrm{~h}$ before attaining the second exponential growth phase. In contrast, growth in trehalose medium was slower, with a generation time of $4 \mathrm{~h}$, and without any perceptible transition phase, indicating that the ability of C. utilis cells to catabolize trehalose requires the expression of the respiratory

Figure 1. Growth of Candida utilis in trehalose or glucose media. C. utilis cells $(800 \mu \mathrm{g}$ dry weight) from a liquid culture in YNB medium containing $1 \%$ trehalose at $3.8 \mathrm{mg}$ (dry weight)/ml were inoculated into $100 \mathrm{ml}$ of YNB media containing $1 \%$ trehalose (filled circles) or $1 \%$ glucose (open circles). The cultures were incubated in an orbital shaker at $28^{\circ} \mathrm{C}$ and $160 \mathrm{rpm}$ and growth was monitored by measuring absorbance at $570 \mathrm{~nm}$.

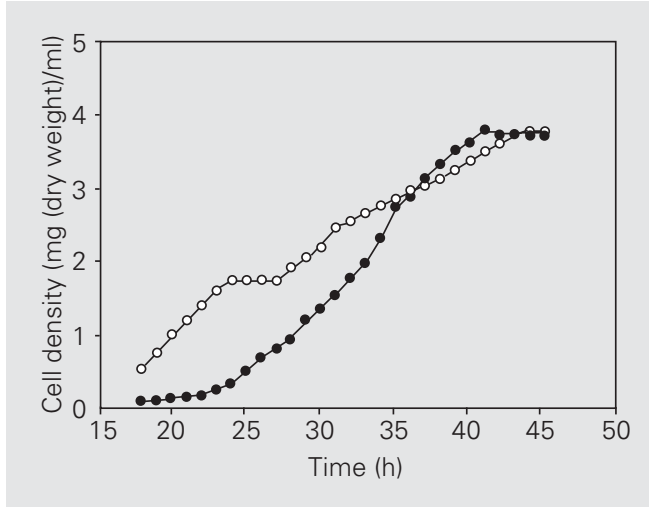

enzymes. Indeed, the determination of the cytochrome spectra of cells harvested at a density of $1 \mathrm{mg}$ (dry weight)/ml from cultures in glucose or trehalose as described previously (20) showed a repressed cytochrome pattern in the former, and an already derepressed cytochrome spectrum in the latter (results not shown). These findings agree with the general assumption that $C$. utilis is unable to ferment trehalose (6), a phenomenon common to many types of yeast that can catabolize aerobically, but not anaerobically, exogenously supplied disaccharides, which are hydrolyzed in the cytosol, even if this yeast ferments one or more of the component hexoses. This phenomenon, called Kluyver effect, has been well documented for maltose in C. utilis $(21,22)$, for trehalose in $S$. cerevisiae (23), and also for sucrose in Debaryomyces yamadae (24). The failure to utilize some disaccharides anaerobically appears to be due to a slowing down of the active sugar transporter, probably because in anaerobiosis there is a lower ATP concentration within the cell, which is insufficient to supply the proton pump optimally and to sustain the proton symport $(25,26)$.

\section{Trehalose is not hydrolyzed by an extracellular trehalase}

No extracellular or cell wall-bound trehalase activity has been reported to occur in C. utilis (10). Since the yeast strain used by these investigators was unable to grow in trehalose, it seems that the absence of an external trehalase might not be a general characteristic of $C$. utilis, but rather a particular feature of the strain used. Indeed, if C. utilis uses external trehalose in a similar way as described for Rhodotorula rubra (3), the absence of an external trehalase could explain the inability of this strain to grow in trehalose. To test whether trehalose could be hydrolyzed by an extracellular trehalase in the strain used in the present study, washed intact cells were incubated with $0.1 \mathrm{M}$ treha- 
buflose for $30 \mathrm{~min}$. As negative and positive controls, reactions using $0.1 \mathrm{M}$ maltose, that is hydrolyzed by a cytoplasmic $\alpha$-glucosidase (20), or 0.1 M sucrose, that is hydrolyzed by a cell wall-bound invertase (27), were carried out. We found that trehalose and maltose might be taken up as such, since glucose was not accumulated in the medium when intact cells were incubated with these disaccharides. In contrast, sucrose was hydrolyzed by an extracellular invertase generating $1230 \pm 120 \mathrm{nmol}$ glucose $\mathrm{min}^{-1} \mathrm{mg}$ cell (dry weight) $)^{-1}$. To rule out the possibility that the estimation of the extracellular glucosidase activities for maltose and trehalose is hampered by the fact that free glucose, if formed, could be rapidly taken up by the cells, additional experiments were performed in the presence of $50 \mathrm{mM} \mathrm{NaF}$, which inhibits the glycolytic pathway, thus preventing sugar uptake (28). Once again, glucose $(1570 \pm 87 \mathrm{nmol}$ min $^{-1} \mathrm{mg}$ cell (dry weight) ${ }^{-1}$ ) was detected solely when sucrose was used as substrate.

\section{Trehalose is taken up by a cytoplasmic membrane transporter}

It has been shown that trehalose can be transported into the cell by high- and lowaffinity transport systems in $S$. cerevisiae $(4,29)$ and in Trichosporon cutaneum (5). To test for the presence of a trehalose transporter, C. utilis cells were incubated with ${ }^{14}[\mathrm{C}]$-trehalose and the captured radioactivity was evaluated. As can be seen in Figure 2, transport of trehalose was linear with respect to cell concentration in the assay (up to 200 $\mu \mathrm{g}$ dry weight) (Figure 2A) and time (up to 1 min) (Figure 2B) in cells harvested after growth in YNB medium with $1 \%$ trehalose as carbon and energy source. Very low counts were obtained in assays using previously boiled cells or performed at $4^{\circ} \mathrm{C}$, indicating that ${ }^{14}[\mathrm{C}]$-trehalose was not nonspecifically binding to membrane or cell wall components. Kinetic assays with substrate concentrations from 1 up to $50 \mathrm{mM}$ showed that the transporter is saturable by the substrate with a $K_{\mathrm{M}}$ of $8 \mathrm{mM}$ for trehalose and a $V_{\mathrm{MAX}}$ of 1.8 $\mu \mathrm{mol}$ trehalose $\mathrm{min}^{-1} \mathrm{mg}$ cell (dry weight) ${ }^{-1}$. The $K_{\mathrm{M}}$ value is within the same range as that previously reported for the $S$. cerevisiae trehalose transporter but $V_{\mathrm{MAX}}$ is at least two orders of magnitude higher $(4,16)$. These results provide support for the existence of a transporter protein in the plasma membrane of C. utilis. In this respect, the only yeast trehalose transporter well characterized is the $A G T 1$-encoded trehalose transporter of S. cerevisiae, which is postulated to have evolved from a duplication of a maltose permease gene. Agt1, in contrast to the maltose transporter, which is highly specific for maltose and turanose, can promote in addition the translocation of isomaltose, $\alpha$ methylglucoside, maltotriose, palatinose, melezitose and trehalose. AGT1 has been cloned and shown to be strongly expressed under maltose growth conditions (30). Evidence for an Agt1-like transporter in C. utilis came from our data which showed that maltose transporter activity of cells grown in the
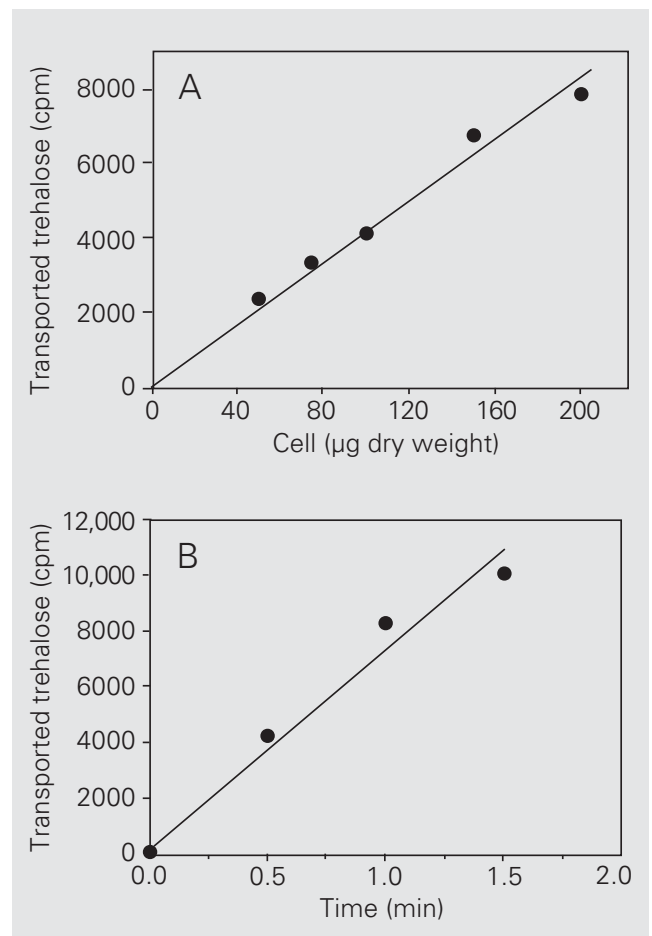

Figure 2. Characterization of the trehalose transporter of Candida utilis. Cells were grown in YNB medium containing $1 \%$ trehalose up to $1.0 \mathrm{mg}$ (dry weight)/ $\mathrm{ml}$. Trehalose transport was assayed as described in Methods using $1.4 \times 10^{5} \mathrm{cpm}\left[{ }^{14} \mathrm{C}\right.$-trehalose per tube. A, Transporter activity as a function of cell mass. The reaction was carried out for $30 \mathrm{~s}$ at room temperature. $B$, Kinetics of the transporter activity. Cells $(100 \mu \mathrm{g}$ dry weight) were incubated in the reaction mixture and transported trehalose measured at the indicated times. 
presence of trehalose was inhibited by trehalose: $1.0 \mathrm{mM}$ trehalose caused $80 \%$ inhibition of the maltose transporter activity, indicating that both sugars can be transported by the same protein.

\section{Trehalose transporter activity is increased during growth in trehalose and maltose}

To determine if the trehalose transporter is constitutively expressed or if its expression is induced only in the presence of trehalose we measured the transporter activity when cells grown in the presence of different carbon sources reached 0.5 and $1.0 \mathrm{mg}$ (dry weight $) / \mathrm{ml}$ (Table 1). The trehalose transporter showed high and comparable activity

\begin{tabular}{|c|c|c|c|c|}
\hline \multirow[t]{2}{*}{$\begin{array}{l}\text { Cell mass } \\
\text { (mg (dry weight)/ml) }\end{array}$} & \multicolumn{4}{|c|}{$\begin{array}{l}\text { Trehalose transporter activity } \\
\text { (nmol trehalose } \text { min }^{-1} \mathrm{mg} \text { cell (dry weight) }{ }^{-1} \text { ) }\end{array}$} \\
\hline & $1 \%$ trehalose & $1 \%$ glucose & $1 \%$ maltose & $3 \%$ glycerol \\
\hline 0.5 & $1225.6 \pm 101.2$ & $36.1 \pm 3.0$ & $1302.1 \pm 97.1$ & $4.5 \pm 0.1$ \\
\hline 1.0 & $1484.0 \pm 122.3$ & $19.1 \pm 1.2$ & $1503.8 \pm 108.7$ & $10.1 \pm 0.2$ \\
\hline
\end{tabular}

Table 2. Trehalase activity during growth of Candida utilis in glucose, maltose and trehalose.

\begin{tabular}{lccc}
\hline $\begin{array}{l}\text { Cell mass } \\
(\mathrm{mg} \text { (dry weight)/ml) }\end{array}$ & \multicolumn{3}{c}{ Trehalase activity $\left(\mathrm{nmol}\right.$ glucose $\left.\mathrm{min}^{-1} \mathrm{mg} \mathrm{protein}^{-1}\right)$} \\
& $1 \%$ glucose & $1 \%$ maltose & $1 \%$ trehalose \\
\hline 0.5 & $1.3 \pm 0.1$ & $28.4 \pm 1.1$ & $43.0 \pm 0.1$ \\
1.0 & $0.9 \pm 0.1$ & $39.0 \pm 3.1$ & $18.6 \pm 2.1$ \\
1.5 & $1.6 \pm 0.2$ & $12.0 \pm 0.3$ & $21.5 \pm 0.3$ \\
2.0 & $0.7 \pm 0.1$ & $16.9 \pm 0.7$ & $31.4 \pm 1.8$ \\
2.5 & $0.7 \pm 0.0$ & $18.0 \pm 0.2$ & $37.2 \pm 1.2$ \\
3.0 & $1.5 \pm 0.1$ & $8.5 \pm 0.1$ & $25.6 \pm 0.5$ \\
3.5 & $2.7 \pm 0.2$ & $22.7 \pm 1.4$ & $56.2 \pm 1.7$ \\
\hline
\end{tabular}

Cells were grown in yeast nitrogen base plus $1 \%$ glucose, $1 \%$ maltose or $1 \%$ trehalose. Cells were harvested at different cell densities as indicated and trehalase activity was measured. Data are reported as means \pm SD of three independent experiments. during cell growth in the presence of $1 \%$ trehalose or $1 \%$ maltose, i.e., $1484.0 \pm 122.3$ and $1503.8 \pm 108.7 \mathrm{nmol}$ trehalose $\mathrm{min}^{-1} \mathrm{mg}$ cell (dry weight) ${ }^{-1}$, respectively. On the other hand, its activity was very low in cells harvested from a glucose or glycerol medium, i.e., $19.1 \pm 1.2$ and $10.1 \pm 0.2 \mathrm{nmol}$ trehalose $\min ^{-1} \mathrm{mg}$ cell (dry weight) ${ }^{-1}$, respectively, less than $2 \%$ of those obtained with trehalose or maltose growth media. These results are similar to those reported for Agt1 activity which was determined in S. cerevisiae cells grown in maltose and in glucose (30). The $A G T 1$ gene was shown to be transcriptionally repressed by Mig1, a transcriptional factor responsible for glucose repression of several genes (31), and activated by MalR, the activator of the expression of the $M A L$ genes (32). This double regulation causes $A G T 1$ to be positively regulated by maltose and repressed by glucose $(29,30)$. Although we have found a similar pattern of activity for the trehalose transporter of $C$. utilis, our results did not discriminate between a trehalose/maltose induction or a double regulation involving also glucose repression.

\section{Trehalase activity is increased during growth in maltose or trehalose}

Next, we determined if trehalase activity could be regulated in a concerted way with the activity of the trehalose transporter. As can be seen in Table 2, trehalase activity showed an oscillatory behavior in all carbon sources studied. Moreover, in all growth stages analyzed, trehalase activities were very low in cells grown in glucose medium, whereas they were always high when maltose or trehalose was used as the carbon source. Trehalase activities varied from 0.7 \pm 0.0 to $2.7 \pm 0.2 \mathrm{nmol}$ glucose $\mathrm{min}^{-1} \mathrm{mg}$ protein $^{-1}$ during growth in glucose, from 8.5 \pm 0.1 to $39.0 \pm 3.1 \mathrm{nmol}$ glucose $\mathrm{min}^{-1} \mathrm{mg}$ protein ${ }^{-1}$ during growth in maltose, and from $18.6 \pm 2.1$ to $56.2 \pm 1.7 \mathrm{nmol}$ glucose $\mathrm{min}^{-1}$ $\mathrm{mg}$ protein ${ }^{-1}$ during growth in trehalose. Un- 
der these growth conditions the increased activity of trehalase could not to be ascribed solely to an effect of catabolite derepression acting on trehalase genes since cells grown in glycerol, a gluconeogenic carbon source, also showed low trehalase activities, similar to those found during growth on glucose (results not shown), suggesting the requirement for an external inducer. To test if this increase in activity could be attributed predominantly to one of the two trehalases existing in C. utilis, we determined the activities of these hydrolases during growth in trehalose. Both acidic and neutral trehalase enzymes contributed to increasing total trehalase activity, although the contribution of neutral trehalase was always higher, i.e., close to $70 \%$ of the total activity, as opposed to $30 \%$ for acidic trehalase (Table 3 ). We have noticed that, at least during growth in YNB containing $1 \%$ trehalose medium, the oscillatory behavior displayed by total trehalase could be imputed to neutral trehalase, since acidic trehalase activity suffered minor variations (Table 3 ). An oscillatory behavior was also seen for neutral trehalase from $S$. cerevisiae during growth in glucose, a phenomenon attributed to trehalase phosphorylation by cAMP-dependent protein kinase acting upon this enzyme $(33,34)$. Thus, we may speculate that both neutral trehalases are regulated in a similar way during the exponential growth stage.

\section{$\alpha$-Glucosidase and maltose transporter activities are increased during growth in maltose or trehalose}

If trehalose transporter and trehalase activities were induced by maltose present in the growth medium, the opposite could also be true, i.e., trehalose may be able to induce the catabolism of maltose. To test this hypothesis, we measured $\alpha$-glucosidase activity (Table 4) from cells grown in medium containing glucose, maltose or trehalose as the carbon source. We found that $\alpha$-glucosidase activity was low in cells grown in glucose (around $1 \mathrm{nmol}$ PNP $\min ^{-1} \mathrm{mg}$ cell (dry weight) $)^{-1}$ ) and was increased 47 to 82 times in cells cultured in maltose or trehalose media. These results clearly indicate that maltose and trehalose activate each other's metabolism, albeit trehalose seems to be less efficient in promoting the increase of $\alpha$ glucosidase activity. As $\alpha$-glucosidase and the maltose transporter are reported to be coregulated in a similar way at a transcriptional level in other yeast (35) we expected the same to occur in C. utilis. Therefore, we measured the activity of the maltose transporter by a colorimetric method (19) using PNPG as substrate. We found that the activ-

Table 3. Neutral and acidic trehalase activity during growth of Candida utilis in trehalose.

\begin{tabular}{|c|c|c|c|}
\hline \multirow{2}{*}{$\begin{array}{l}\text { Cell mass } \\
\text { (mg (dry weight)/ml) }\end{array}$} & \multicolumn{3}{|c|}{ Trehalase activity ( $\mathrm{nmol}$ glucose $\mathrm{min}^{-1} \mathrm{mg}$ protein-1) } \\
\hline & Total & Neutral & Acidic \\
\hline 0.5 & $43.0 \pm 1.5$ & $34.7 \pm 1.2$ & $9.1 \pm 0.8$ \\
\hline 1.0 & $18.6 \pm 0.6$ & $12.8 \pm 0.3$ & $8.5 \pm 0.6$ \\
\hline 1.5 & $21.5 \pm 1.5$ & $13.8 \pm 0.9$ & $8.7 \pm 0.2$ \\
\hline 2.0 & $31.4 \pm 1.8$ & $23.2 \pm 0.1$ & $15.7 \pm 0.9$ \\
\hline 2.5 & $37.2 \pm 0.7$ & $24.8 \pm 1.1$ & $11.3 \pm 0.2$ \\
\hline 3.0 & $25.6 \pm 1.3$ & $14.9 \pm 1.7$ & $8.3 \pm 1.7$ \\
\hline 3.5 & $56.2 \pm 2.6$ & $48.4 \pm 0.5$ & $8.7 \pm 0.2$ \\
\hline
\end{tabular}

Cells were grown in yeast nitrogen base medium containing $1 \%$ trehalose, harvested at different cell culture densities and total, neutral, and acidic trehalase activities were determined as described in Material and Methods. Data are reported as means \pm SD of three independent experiments.

Table 4. $\alpha$-Glucosidase activity during growth of Candida utilis in glucose, maltose and trehalose.

\begin{tabular}{lccc}
\hline $\begin{array}{l}\text { Cell mass } \\
\text { (mg (dry weight)/ml) }\end{array}$ & \multicolumn{3}{c}{$\begin{array}{c}\alpha-\text { Glucosidase activity } \\
\left.\text { (nmol PNP } \text { min }^{-1} \text { mg cell (dry weight) }\right)^{-1} \text { ) }\end{array}$} \\
\cline { 2 - 4 } & $1 \%$ glucose & $1 \%$ maltose & $1 \%$ trehalose \\
\hline 0.5 & $0.15 \pm 0.03$ & $78.1 \pm 5.3$ & $47.9 \pm 5.1$ \\
1.0 & $0.06 \pm 0.02$ & $78.6 \pm 9.1$ & $47.5 \pm 2.1$ \\
1.5 & $1.15 \pm 0.09$ & $79.5 \pm 6.3$ & $47.3 \pm 3.3$ \\
2.0 & $1.17 \pm 0.07$ & $82.1 \pm 2.7$ & $57.8 \pm 2.8$
\end{tabular}

Cells were grown in yeast nitrogen base plus $1 \%$ glucose, $1 \%$ maltose or $1 \%$ trehalose. Cells were harvested at different cell densities as indicated and the $\alpha$ glucosidase activity was measured. Data are reported as means \pm SD of one experiment carried out in triplicate. PNP, p-nitrophenol. 
Figure 3. Induction and catabolite repression of $\alpha$-glucosidase and maltose transporter activities in Candida utilis. Cells (50 mg dry weight) from a liquid culture in YNB medium containing $1 \%$ glucose at $3.3 \mathrm{mg}$ of cells (dry weight)/ml were reinoculated into $100 \mathrm{ml}$ of fresh YNB media containing $1 \%$ glucose, $1 \%$ trehalose or $1 \%$ maltose. Maltose transporter (panel A) and $\alpha$-glucosidase (panel B) activities were determined in cell samples collected at the times indicated. PNP, p-nitrophenol. ity of the maltose transporter, which is undetectable during growth in glucose, is increased up to 3.5 and $7.1 \mathrm{nmol}$ PNP $\mathrm{min}^{-1} \mathrm{mg}$ cell (dry weight) ${ }^{-1}$ in cells harvested at the density of $1 \mathrm{mg}$ (dry weight)/ml in trehalose and maltose medium, respectively, supporting our hypothesis. Interplay between the roles of these disaccharides in inducing the expression of the proteins necessary to promote each other's catabolism has already been shown to occur in E. coli (13) and Thermococcus litoralis (36).

To examine the above hypothesis, maltose transporter and $\alpha$-glucosidase activities were measured in $C$. utilis cells grown up to the stationary phase in glucose medium and up to $6 \mathrm{~h}$ after the transfer to fresh maltose, trehalose or glucose media (Figure 3). Both activities were low in stationary phase cells $(0.7 \mathrm{nmol}$ PNP min $^{-1} \mathrm{mg}$ cell (dry weight) ${ }^{-1}$ and 16.0 nmol PNP min $^{-1} \mathrm{mg}$ cell (dry weight) ${ }^{-1}$ for the transporter and $\alpha$-glucosidase activities, respectively). After $2 \mathrm{~h}$ in maltose or trehalose medium, maltose transporter and $\alpha$ glucosidase activities started to increase,
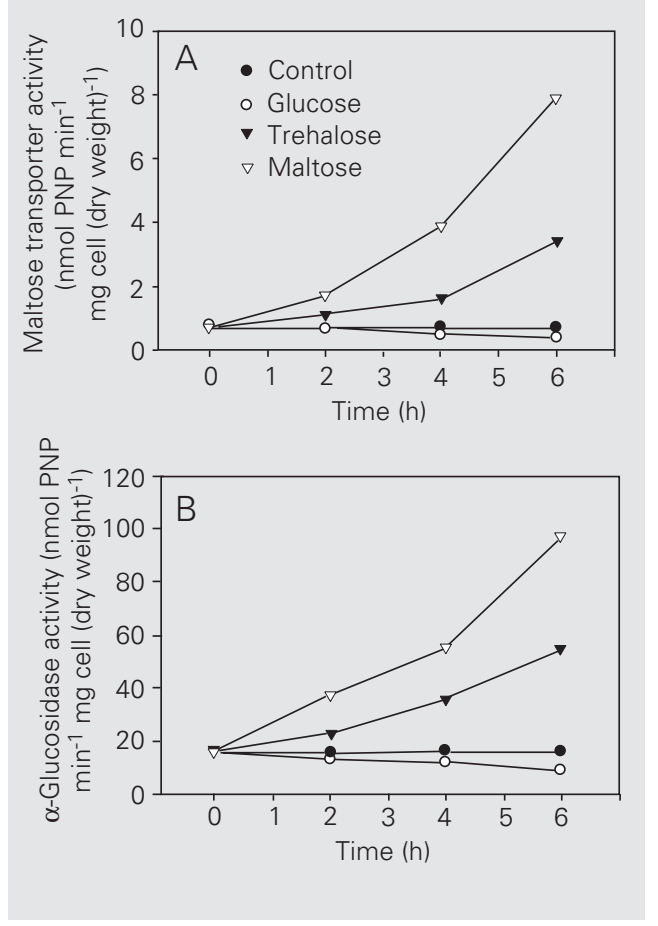

reaching levels similar to those observed during normal growth in these media after $6 \mathrm{~h}$ of incubation. In contrast, the control and the culture in fresh glucose medium did not show any increase in the tested activities. Moreover, the addition of $1 \%$ glucose to the trehalose or maltose medium abolished the observed induction of the maltose transporter and $\alpha$-glucosidase activities (result not shown). Therefore, glucose exhaustion is not sufficient for the full expression of the transporter and glucosidase activities. For this to occur, the presence of maltose or trehalose is necessary. Thus, in C. utilis, protein activities necessary for maltose utilization are repressed by glucose and induced by maltose or trehalose. Indeed, in S. cerevisiae the trehalose transporter is induced by maltose $(29,30)$ but, to our knowledge, we show here for the first time that trehalose is able to induce the catabolism of maltose in yeast.

The results obtained here indicate that in C. utilis the first step in the catabolism of trehalose involves its entry into the cell by means of a trehalose membrane transporter. Inside the cell, trehalose is hydrolyzed by neutral and/or acidic trehalases, both of which showed increased activities in the presence of external trehalose. The activities of the trehalose transporter, both trehalases as well as $\alpha$-glucosidase and the maltose transporter were increased when maltose or trehalose, but not glucose, was used as the carbon source. Thus, it appears that in C. utilis maltose and trehalose, or a common metabolite of their catabolism, are able to regulate the activities of the specific enzymes and transporters which are needed for the initial steps of each other's catabolism. Further studies are necessary to elucidate additional aspects of the catabolism of trehalose in $C$. utilis: if the transport of maltose and trehalose is performed by a single protein system; what trehalase activity - neutral or acid trehalase - preferentially hydrolyses the internalized trehalose, and finally the nature of the inducer molecule. 


\section{References}

1. Barnett JA (1981). The utilization of disaccharides and some other sugars by yeasts. Advances in Carbohydrate Chemistry and Biochemistry, 39: 347-404.

2. Elbein A (1974). The metabolism of $\alpha, \alpha$-trehalose. Advances in Carbohydrate Chemistry and Biochemistry, 30: 227-256.

3. Mansure JJ, Silva JT \& Panek AD (1992). Characterization of trehalase in Rhodotorula rubra. Biochemistry International, 28: 693-700.

4. Kotik A \& Michaljanicová D (1979). Uptake of trehalose by Saccharomyces cerevisiae. Journal of General Microbiology, 110: 323-332.

5. Mörtberg M \& Neujahr HY (1986). Transport and hydrolysis of disaccharides by Trichosporon cutaneum. Journal of Bacteriology, 168: 734-738.

6. Lodder J (1970). The Yeast, a Taxonomic Study. North-Holland Publishing Company, Amsterdam, The Netherlands.

7. Londesborough J \& Varimo K (1984). Characterization of two trehalases in baker's yeast. Biochemical Journal, 219: 511-518.

8. Kopp M, Muller H \& Holzer H (1993). Molecular analysis of the neutral trehalase gene from Saccharomyces cerevisiae. Journal of Biological Chemistry, 268: 4766-4774.

9. Nwaka S, Mechler B \& Holzer H (1996). Deletion of the ATH1 gene in Saccharomyces cerevisiae prevents growth on trehalose. FEBS Letters, 386: 235-238.

10. Arguelles JC \& Gacto M (1985). Evidence for regulatory trehalase in Candida utilis. Canadian Journal of Microbiology, 31: 529-537.

11. Arguelles JC, Vicente-Soler J \& Gacto M (1986). Protein phosphorylation and trehalase activation in Candida utilis. FEMS Microbiology Letters, 34: 361-365.

12. Carrilo D, Vicente-Soler J, Fernandez J, Soto T, Cansada J \& Gacto M (1995). Activation of cytoplasmic trehalase by cyclic-AMP-dependent and cyclic-AMP-independent signaling pathways in the yeast Candida utilis. Microbiology, 141: 679-686.

13. Decker K, Gerhardt F \& Boss W (1999). The role of the trehalose system in regulating the maltose regulon of Escherichia coli. Molecular Microbiology, 32: 777-788.

14. Layne E (1957). Spectrophotometric and turbidimetric methods for measuring protein. Methods in Enzymology, 3: 447-454.

15. Stambuk BU, Crowe JH, Crowe LM, Panek AD \& de Araujo PS (1993). A dependable method for the synthesis of $\left[{ }^{14} \mathrm{C}\right]$ trehalose. Analytical Biochemistry, 212: 150-153.

16. Zimmermann FK \& Eaton NR (1974). Genetics of induction and catabolite repression of maltase synthesis in Saccharomyces cerevisiae. Molecular and General Genetics, 134: 165-175.

17. Crowe JH, Panek AD, Crowe LM, Panek AC \& de Araujo PS (1991). Trehalose transport in yeast cells. Biochemistry International, 24: 721-730.

18. Sims AP, Kopetzki E, Schulz B \& Barnett JA (1984). The use of phenolic glycosides for studying the aerobic or anaerobic transport of disaccharides into yeast. Journal of General Microbiology, 130: 1933-1940.

19. Peinado JM, Barbero A \& van Uden N (1987). Repression and inactivation by glucose of the maltose transport system of Candida utilis. Applied Microbiology and Biotechnology, 26: 154-157.

20. Borralho LM, Panek AD, Malamud DR, Sanders HK \& Mattoon JR
(1983). In situ assay for 5-aminolevulinate dehydratase and application to the study of a catabolite repression-resistant Saccharomyces cerevisiae mutant. Journal of Bacteriology, 156: 141-147.

21. Weusthuis RA, Luttik MA, Scheffers WA, van Dijken JP \& Pronk JT (1994). Is the Kluyver effect in yeast caused by product inhibition? Microbiology, 140: 1723-1729.

22. Kaliterna J, Weusthuis RA, Castrillo JI, van Dijken JP \& Pronk JT (1995). Transient responses of Candida utilis to oxygen limitation: regulation of the Kluyver effect for maltose. Yeast, 11: 317-325.

23. Malluta EF, Decker P \& Stambuk BU (2000). The Kluyver effect for trehalose in Saccharomyces cerevisiae. Journal of Basic Microbiology, 40: 199-205

24. Kaliterna J, Weusthuis RA, Castrillo JI, van Dijken JP \& Pronk JT (1995). Coordination of sucrose uptake and respiration in the yeast Debaryomyces yamadae. Microbiology, 141: 1567-1574.

25. Barnett JA (1992). Some controls on oligosaccharide utilization by yeasts: the physiological basis of the Kluyver effect. FEMS Microbiology Letters, 79: 371-378.

26. Goffrini P, Ferrero I \& Donnini C (2002). Respiration-dependent utilization of sugars in yeasts: a determinant role for sugar transporters. Journal of Bacteriology, 184: 427-432.

27. Mendoza CG \& Villanueva JR (1967). Preparation and composition of the protoplast membrane of Candida utilis. Biochimica et Biophysica Acta, 135: 189-195.

28. Silveira MCF, Carvajal E \& Bon EPS (1996). Assay for in vivo yeast invertase activity using NaF. Analytical Biochemistry, 238: 26-28.

29. Stambuk BU, Panek AD, Crowe JH, Crowe LM \& de Araujo PS (1998). Expression of high-affinity trehalose- $\mathrm{H}^{+}$symport in Saccharomyces cerevisiae. Biochimica et Biophysica Acta, 1374: 118-128.

30. Han E, Cotty F, Sottas HJ \& Micheles CA (1995). Characterization of AGT1 encoding a general $\alpha$-glucoside transporter from Saccharomyces. Molecular Microbiology, 17: 1093-1107.

31. Nehlin JO \& Ronne H (1990). Yeast MIG1 repressor is related to the mammalian early growth response and Wilms' tumour finger proteins. EMBO Journal, 9: 2891-2898.

32. Hong SH \& Marmur J (1987). Upstream regulatory regions controlling the expression of the yeast maltase gene. Molecular and Cellular Biology, 7: 2477-2483.

33. Coutinho CC, Silva JT \& Panek AD (1992). Trehalase activity and its regulation during growth of Saccharomyces cerevisiae. Biochemistry International, 26: 521-530.

34. Souza AC, De Mesquita JF, Panek AD, Silva JT \& Paschoalin VMF (2002). Evidence for a modulation of a neutral trehalase activity by $\mathrm{Ca}^{2+}$ and CAMP signaling pathways in Saccharomyces cerevisiae. Brazilian Journal of Medical and Biological Research, 35: 11-16.

35. Levine J, Tanouye L \& Michels CA (1992). The UAS(MAL) is a bidirectional promoter element required for the expression of both the MAL61 and MAL62 genes of the Saccharomyces MAL6 locus. Current Genetics, 22: 181-189.

36. Xavier KB, Martins LO, Peist R, Kossmann M, Boos W \& Santos H (1996). High-affinity maltose/trehalose transport system in the hyperthermophilic archaeon Thermococcus litoralis. Journal of Bacteriology, 178: 4773-4777. 